\title{
INHIBITIVE EFFECT OF ATENOLOL ON THE CORROSION OF ZINC IN HYDROCHLORIC ACID
}

\author{
Atheel H. Alwash ${ }^{1}$, Dhuha H. Fadhil, Ali Abd Ali, Fatma Abdul-Hameed \\ and Emad Yousif* \\ Department of Chemistry, College of Science, Al-Nahrain University, Baghdad, Iraq \\ *E-mail : emad_yousif@hotmail.com
}

\begin{abstract}
Herein, we report the using of atenolol drug as a green corrosion inhibitor for zinc metal. Corrosion inhibitory effect of atenolol on zinc in $1 \mathrm{M} \mathrm{HCl}$ was explored using the gravimetric method. The findings revealed that atenolol inhibited zinc corrosion in $\mathrm{HCl}$ solution and corrosion rate decreased with increasing the atenolol concentration. The optimum surface coverage was determined as 0.93 at $500 \mathrm{ppm}$ atenolol concentration. Chemical computations were exploited to determine the electronic characteristics of atenolol such as highest occupied molecular orbital energy and lowest unoccupied molecular orbital energy (HOMO and LUMO, respectively). These important parameters obtained and elucidated which also confirmed the experimental findings. The findings (experimental and computational) demonstrated that the corrosion inhibition capacity increased with increasing the $\mathrm{E}_{\mathrm{HOMO}}$ value and decreasing the $\mathrm{E}_{\mathrm{LuMO}}$ value.
\end{abstract}

Keywords: Atenolol, Corrosion inhibition, adsorption, electronic properties, zinc applications

() RASĀYAN. All rights reserved

\section{INTRODUCTION}

Zinc has been used in numerous industrial applications, especially in protecting steel from corrosion. ${ }^{1}$ One of the feasible ways to protect metals from corrosion is the application of a corrosion inhibitor. ${ }^{2}$ Organic heterocyclic compounds which have phosphorous, nitrogen, sulfur and oxygen can be exploited as corrosion inhibitors. Their inhibitory effect stems from the fact that the aforementioned electron rich atoms can act as electron donors when attached to metals. These heterocyclic compounds adsorb to the surface of metals by physical or chemical adsorption and forming a defensive or a protecting layer against the highly corrosive alkaline or acidic environment. ${ }^{3-6}$

Most importantly, the adsorption into the surface of the metal is kinetically and thermodynamically controlled process which can be reversed at any instance. ${ }^{7}$ Computational chemical predictions were implemented to determine the formation of atenolol in the vapor phase using Hyper Chem software version 7. The software was very beneficial via using the semi-empirical and Perturbated Molecular theory (PM3) calculations. As a matter of fact, these protocols often short computation times, and lead to qualitatively descriptive information which is summarized in later sections. Frankly speaking, PM3 can give very relevant results to the experimental results. Additionally, the semi-empirical PM3 method makes uses of an accurate procedure to predict electronic properties of atenolol, namely, $\mathrm{E}_{\mathrm{HOMO}}$ and ELUMo.

In this article, weight loss measurements are employed to study the corrosion and corrosion inhibition of Zinc in $1 \mathrm{M} \mathrm{HCl}$. Along with the experimental findings, there is a sufficient computational information confirm the corrosion inhibition effect of atenolol indicative of a prospective usage of it as an eco-friendly corrosion inhibitor.

\section{EXPERIMENTAL}

Zinc plates were obtained from zinc-graphite batteries and prepared with the following dimensions $(8 \mathrm{~cm}$ X $2 \mathrm{~cm}$ X 0.5mm), (L X W X H). HCl was supplied from Sigma-Aldrich (35-37\%), AR-Grade. Ethanol (96\%), atenolol was supplied by Samara drug industry, Iraq, and acetone was supplied by Merck. All 
chemicals were used without any further purification. Ultrapure water $(18.2 \Omega . \mathrm{cm})$ was used for preparing solutions and washing.

A stock solution of $1000 \mathrm{ppm}$ atenolol in ultrapure water was prepared and then a set of (100-500 ppm) atenolol solutions were prepared by sequential dilution.

Zinc plates were washed thoroughly few times by acetone, followed by $96 \%$ ethanol and finally by ultrapure water, and then dried by a clean tissue. These plates were scrubbed by emery paper and washed also by acetone, ethanol, and water, dried by a clean tissue and stored in a desiccator until use.

The zinc plates were weighed and soaked in a $1 \mathrm{M} \mathrm{HCl}$ solution over the course of 175 minutes at 25 minutes interval.

In each atenolol solution $(100,200,300,400$, and 500ppm), a zinc plate was immersed and left to equilibrate for 60 minutes. Thereafter, the plates were immersed in $1 \mathrm{M} \mathrm{HCl}$ solution and measured the weight difference for 225 minutes at 25 minutes interval and at room temperature.

The concentration of atenolol was determined via measuring the absorbance of atenolol solution using a UV-Visible spectrophotometer (Shimadzu-1601) at $\lambda_{\max }=275 \mathrm{~nm}$. For adsorption experiments, solutions were shaken using a flask shaker (Gallenkamp) for a 25 minutes interval, placed in the centrifuge for 20 minutes at $4400 \mathrm{rpm}$ and then the supernatant was put in a quartz cell (Starna, 10mm path length, open top)to measure the absorbance and then calculate the concentration of atenolol after the adsorption using Beer-Lambert equation.

\section{RESULTS AND DISCUSSION}

Determining the corrosion of zinc was achieved by employing the gravimetric method by which we monitored the weight loss in the zinc plate upon corrosion. The weight was measured at 25 minutes interval over the course of 175 minutes. The weight difference then used to calculate the corrosion rate (CR) using the following formula:

$$
C R=\Delta m / \Delta t
$$

Where $\Delta m$ is the weight difference before and after the immersion in $\mathrm{HCl}$, and $\Delta \mathrm{t}$ is the time interval.

The atenolol inhibitor was introduced to the zinc in different concentrations $(100,200,300,400$, and 500 ppm) and the weight difference was measured at 25 minutes interval over the course of 175 minutes as depicted in Fig.-1.

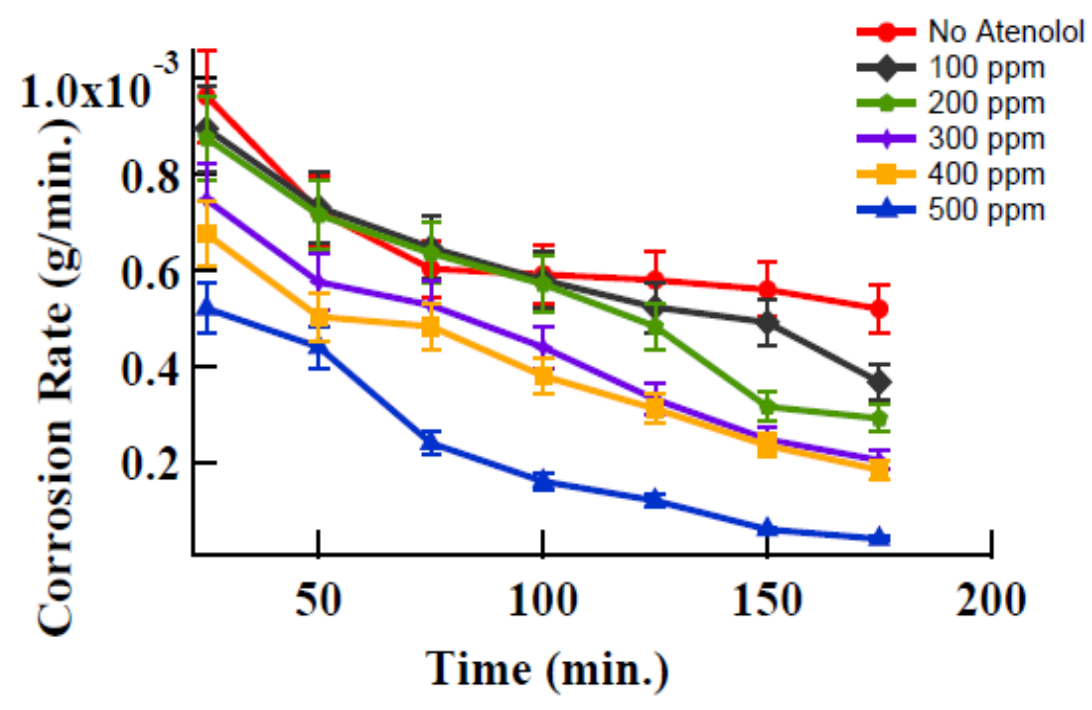

Fig.-1: CR versus time for the zinc in $1 \mathrm{M} \mathrm{HCl}$ (red circles) and in the presence of atenolol inhibitor at different concentrations (100-500 ppm). The error bars represent the error come from measuring the weight which is within $10 \%$ in this case. 
The CR was decreased with increasing the concentration of the atenolol which is attributed to the fact that atenolol formed a protective layer and prevented the zinc metal of being exposed to the $\mathrm{HCl}$. There was a significant decrease in CR at $500 \mathrm{ppm}$ in compared to the CR in the absence of atenolol which confirms that atenolol was a good inhibitor. We suppose that there are also some other reasons for that significant drop in the CR which will be discussed later on.

Another important parameter was also calculated is that the surface coverage $(\theta)$ using the following formula:

$$
\theta=1-\left(C R_{w / i n h} / C R_{w / o}\right)
$$

Where $C R_{w / i n h}, C R_{w / o}$ are the corrosion rate with and without the inhibitor respectively.

The surface coverage was calculated for atenolol (100-500 ppm) which was 0.93 at $500 \mathrm{ppm}$ as shown in Fig.-2. The implication behind calculating the surface coverage is that it expresses the number of adsorbed sites to the number of available sites on the zinc plate. Based on the dimensions of the zinc plate that used in this study, we calculated the surface area of the zinc plate (rectangular) which was $3.4 \times 10^{15}$ $\mathrm{nm}^{2}$. The whole length of atenolol molecule was calculated as well which was $1.85 \mathrm{~nm}$ (from end to end). Thus it can be inferred that this area will enough to accommodate $1.84 \times 10^{14}$ molecule, and that is why the $500 \mathrm{ppm}$ was high enough to provide a high surface coverage which was approaching unity.

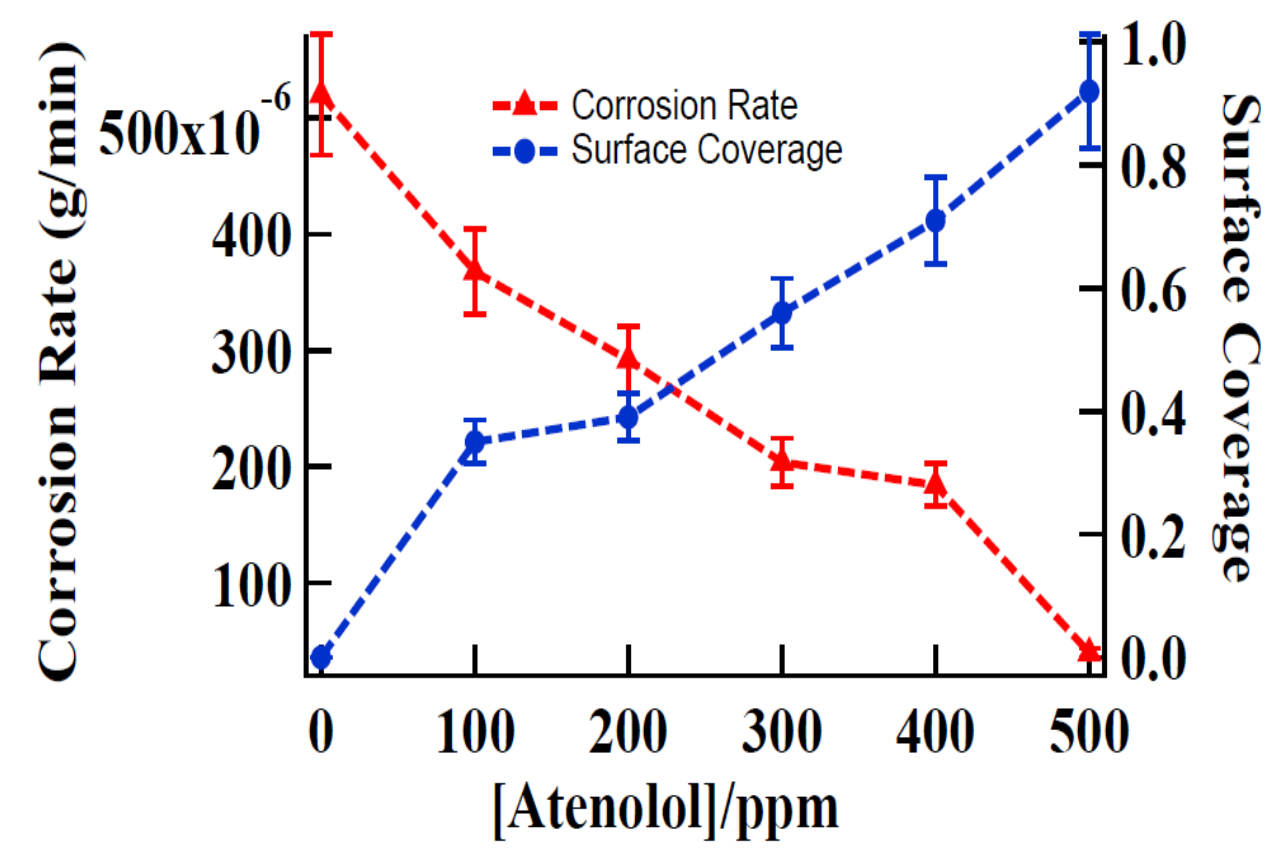

Fig.-2: CR (red triangles) and surface coverage (blue circles) versus atenolol concentration in ppm. Error bars show $10 \%$ error due to the gravimetric method.

Based on the literature ${ }^{8-12}$, and the current findings so far, the atenolol was chemically or physically adsorbed to the zinc. According to the chemical structure of atenolol (Fig.-3a), it is quite phenomenal that the adsorption occurred between any electron rich atoms (e.g. oxygen or nitrogen). However, the scenario here is different for few reasons:

1. The $\mathrm{NH}_{2}$ group in the amide cannot attach to the zinc, as the lone pair of electrons is delocalized by resonance phenomenon.

2. The oxygen in $-\mathrm{O}-$ is linked to the benzene ring and its lone pair also contributed through resonance phenomenon.

3. There might be a possibility that zinc forms a coordinate bond with the hydroxyl group ( $-\mathrm{OH})$ and the $2^{\circ}$ amine group (-NH). 
Here it should be noted that the lone pairs on nitrogen and oxygen are localized. However, the suggested complex structure (Fig.-3b) can be true if the molecule configuration of atenolol was not changed in such a way that maintains the hydroxyl and $2^{\circ}$ amine group parallel to each other.

(a)<smiles>[14CH3]N(CC(O)COc1ccc(CC(N)=O)cc1)OC=O</smiles>

(b)

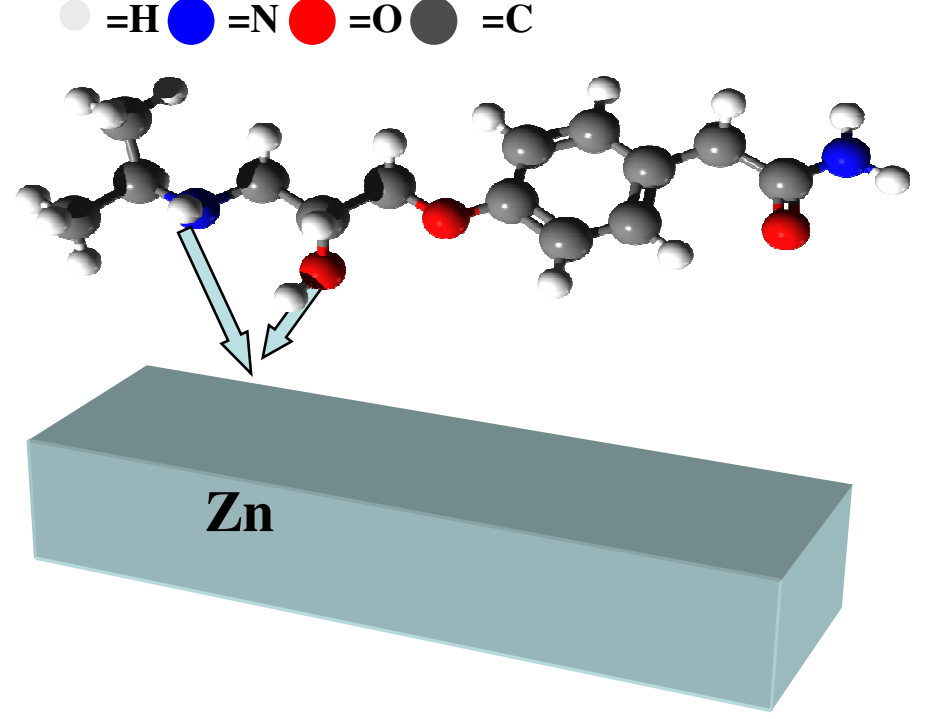

Fig.-3: (a) The chemical structure of atenolol showing the possible adsorption sites; (b) A three-dimensional structure of atenolol with nitrogen and oxygen atoms facing the zinc plate.

Theoretically speaking, the formation of a monolayer of atenolol on zinc can be completed once the equilibrium is established as shown below in the following chemical equilibrium:

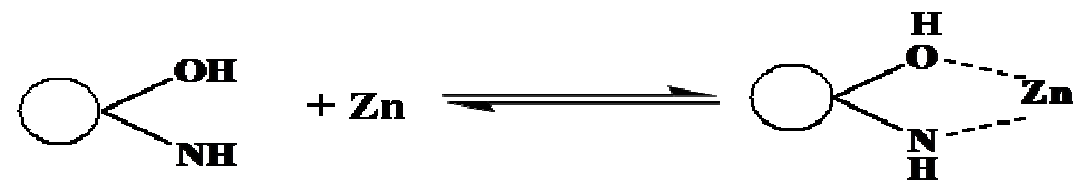

However, the adsorption of does not stop at the monolayer level, as it may continue to form a multilayer. In this regard, a salient phenomenon worth mentioning is that benzene rings can form dimers, so-called " $\pi$ - $\pi$ stacking", as they bound by affording $2-3 \mathrm{k}$. cal/mol at a separation distance of around $0.5 \mathrm{~nm}$ between their aromatic nuclei. ${ }^{13-14}$.

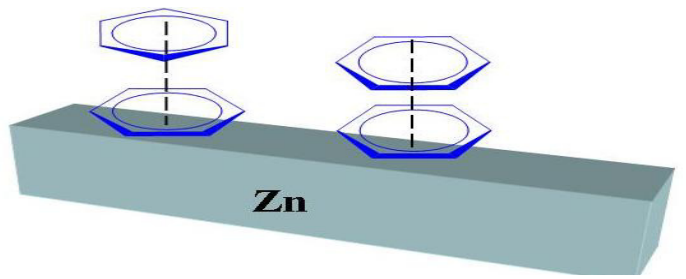

Fig.-4: The $\pi-\pi$ stacking between benzene rings. The structure on the left is the T-shaped, and the structure on the right is the sandwich form. 
There are three forms the benzene dimer can adopt. ${ }^{14}$ Nevertheless, the most stable forms are the sandwich and the T-shaped forms as shown in Fig.-4.

In fact, this gives a support to the current findings which showed that the CR did not stop dropping at $500 \mathrm{ppm}$. To further elucidate the mechanistic pathway of atenolol ligation to the zinc surface, an adsorption experiment was performed.

The adsorption isotherm showed that the adsorption was most probably a Freundlich isotherm as depicted in Fig.-5 (a, b, and c). In this case, the adsorption of atenolol does not discontinue after forming a monolayer which is quite consistent with what has been experimentally found based on gravimetric method.

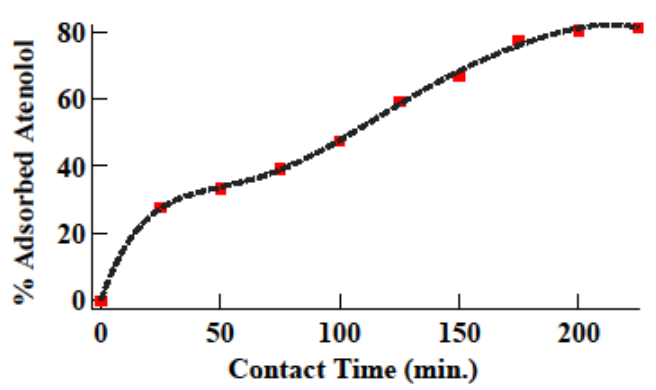

(a)

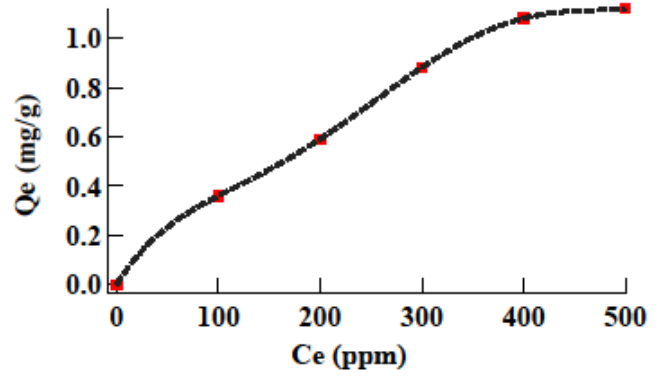

(b)

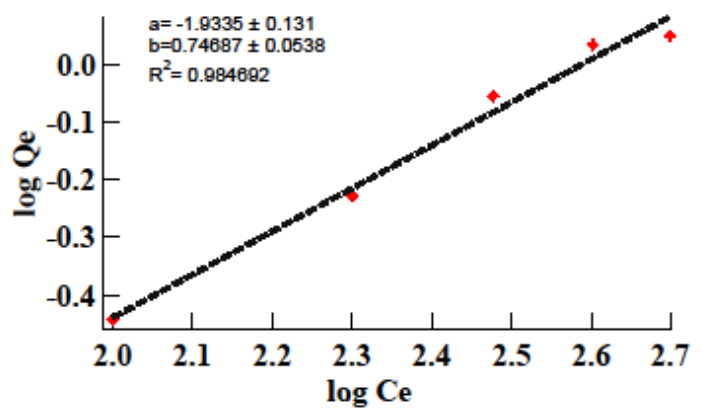

(c)

Fig.-5: (a)The contact time of adsorption of atenolol (0-225 minutes), (b) The adsorption isotherm of atenolol at room temperature, (c)The logarithmic plot Freundlich isotherm showing a linear relationship with reasonable correlation coefficient.

The Freundlich equation can be represented as follows:

$\log Q e=\log K_{F}+1 / n \log C e$

Where, Qe, and $\mathrm{Ce}$ is the adsorbate quantity at equilibrium $(\mathrm{g})$ and the concentration of atenolol at equilibrium $(\mathrm{mg} / \mathrm{L})$. The $\mathrm{K}_{\mathrm{F}}$ and $1 / \mathrm{n}$ are defined as Freundlich constants, where $\mathrm{KF}$ is the adsorption capacity, and $1 / \mathrm{n}$ represents the adsorption intensity. ${ }^{15}$

There was a reasonable linear adsorption isotherm when $\log$ Qe was plotted versus $\log$ Ce as shown in Figure-5(c). The correlation coefficient was 0.9847, and the values of $\mathrm{K}_{\mathrm{F}}$ was -1.93 , and $\mathrm{n}=1.34$.

We suppose also that atenolol molecule in aqueous solution might form a hydrogen bonding with another molecule which is realistically acceptable knowing that all solutions were prepared in water.

In order to give a clearer picture for the corrosion inhibition, and adsorption of atenolol on zinc we performed a computational study to the atenolol inhibitor. The purpose of this computational study is to obtain some useful information regarding the electronic properties of atenolol to find out the correlation between atenolol structure and its inhibition capacity. The calculations for geometry optimization were 
RASĀYAN J. Chem.

Vol. 10 | No. 3 |922 - 928 | July - September | 2017

conducted using the semi-empirical calculations with a PM3 protocol which has been established to give reasonable results. ${ }^{17-18}$

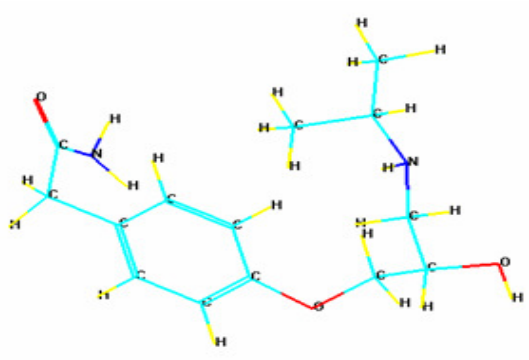

(a)

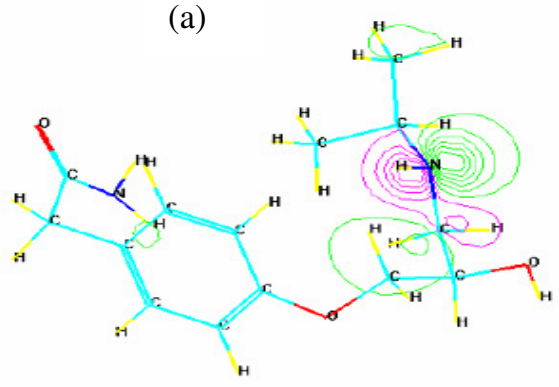

(c)

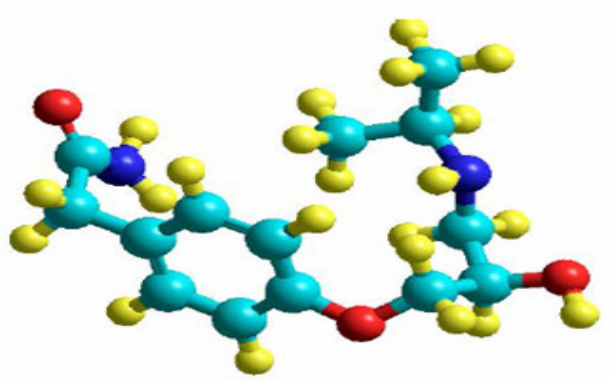

(b)

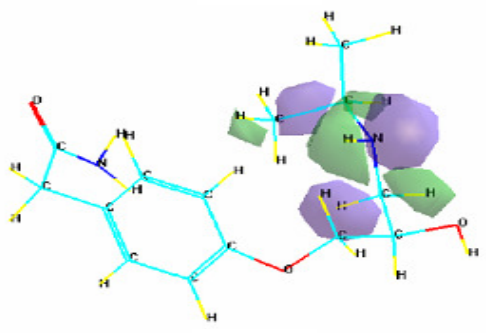

(d)

Fig.-6: (a)Structure of atenolol in a stick model,(b) Structure of atenolol in a ball and stick model, (c) 2D contour map of atenolol structure, (d)3D contour map of atenolol structure.

The contour map (Fig.-6c) showed the highest dipole moment which was on the nitrogen atom of the $2^{\circ}$ amine. The direction of the dipole moment in the atenolol molecule is towards that amine group. That gives another support to the previous claim that this amine group is one of the possible anchors which can adsorb to the zinc.

The reasonable of the way of correlating the electronic configuration of atenolol obtained from the computation and the experimental data (corrosion and adsorption isotherms) is via calculating the energy gap and consequently the $\mathrm{E}_{\text {Hомо }}$ and $\mathrm{E}_{\mathrm{Lumo}}$. This was achieved using PM3 calculations to get the geometry optimized structure of atenolol, calculate the energies of HOMO, LUMO and other important indices as illustrated in Table-1.

Table-1: The calculated quantum chemical parameters using PM3 method

\begin{tabular}{l|l|l|l|l}
\hline Compound & $\mathrm{E}_{\text {HOMO }}(\mathrm{eV})$ & $\mathrm{E}_{\text {LUMO }}(\mathrm{eV})$ & $\Delta \mathrm{E}(\mathrm{eV})$ & $\mu($ Debye $)$ \\
\hline Atenolol & -9.283 & -0.267 & -9.016 & 3.016 \\
\hline
\end{tabular}

The energy difference or the band gap $(\Delta \mathrm{E})$ between the HOMO and LUMO energy levels of atenolol is a crucial factor, as, the low absolute value of $\Delta \mathrm{E}$ gives good inhibition capacities ${ }^{19}$. Furthermore, the adsorption of atenolol is related to the $\mathrm{E}_{\text {Hомо }}$ and $\mathrm{E}_{\mathrm{LUMO}}{ }^{20-22}$, since the higher $\mathrm{E}_{\mathrm{HOMO}}$ means that the atenolol has a higher tendency to donate electrons towards the zinc metal. Additionally, lower $\mathrm{E}_{\mathrm{Lumo}}$

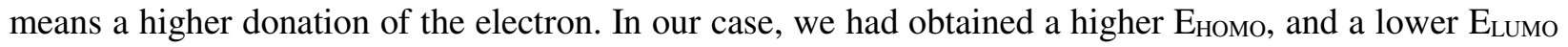
which confirms that atenolol has a good inhibition capacity.

\section{CONCLUSION}

In conclusion, atenolol showed a good corrosion inhibitive effect for the zinc corrosion in $\mathrm{HCl}$ solution. This corrosion inhibition was tested via implementing weight loss measurements (gravimetric method), 
adsorption experiments, and chemical computations. All findings were reasonably consistent and suggest using atenolol as a green corrosion inhibitor as it significantly hindered the corrosion rate of zinc.

\section{ACKNOWLEDGEMENT}

A special thank goes to Department of Chemistry, College of Science, Al-Nahrain University for their outstanding assistance to perform this research.

\section{REFERENCES}

1. B. Shylesha, T. Venkatesha, B. Praveen, Chem. Pharm. Res., 4, 3414 (2012).

2. S. Odoemelam, E. Ogoko, B. Ita, N. Eddy, Electrochim. Acta, 27, 57 (2009).

3. A. H Al-Obaidy, A. Kadhum, S. Al-Baghdadi, A. Al-Amiery, A. A. Kadhum, E. Yousif, A. B. Mohamad, , Inter. J. electrochem. Sci., 10, 3961(2015).

4. E. Yousif, Y-F. Win, A. Al-Hamadani, A. Al-Amiery, A. A. Kadhum, A. B. Mohamad, Inter. J. electrochem. Sci., 10, 1708 (2015).

5. N. Assad, F. Abdul-Hameed, A. Balakit, E. Yousif, JNUS, 18 (2), 69(2015).

6. A. H. Kadhum, A. Mohamad,L. Hammed., A. A. Al-Amiery, N. G.Hooi San, A. Y. Musa, Mater., 7, 4335 (2014).

7. J. Stewart, J. Comp. Chem., 10, 209 (1989).

8. N. Al-Mobarak, , K. Khaled,, N. Mohamed, K. Abdel-Azim, N. Abdelshafi, Arab. J. Chem., 3, 33 (2010).

9. O. Abiola, A. James, Corr. Sci., 52, 661(2010).

10. O. Abiola, N. Oforka, E. Ebenso, N. Nwinuka, Anti-Corr. Meth. and Mater. 54, 219(2007).

11. M. Chigondo , F. Chigondo, J. of Chem., 2016, 1 (2016).

12. M. Oki, K. Oki, J. Otaigbe, S. Otikor, J. of Mater., 2013, 1(2013).

13. M. Sinnokrot, E. Valeev, C, Sherrill,. J. Am. Chem. Soc., 124 (36), 10887 (2002).

14. G. McGaughey, M. Gagné, A. Rappé, J. Biol. Chem., 273 (25): 15458(1998).

15. A. K. Singh, S. Mohapatra, and B. Pani, J. Indust. Eng. Chem., 33, 288(2016).

16. N. Gupta, S. Amritphale, N. Chandra, Biores. Technol., 101(10), 3355 (2010).

17. K. Sourav, A. Saha, G. Pritam, S. Dipankar, B. Priyabrata, PCCP., 17, 5679 (2015).

18. S. Quraishi, M. Quraishi, R. Quraishi, Open Corros. J., 29, 83 (2009).

19. M. El-Naggar, Corros. Sci., 49, 2226 (2007)

20. A. Ehsani, M. Mahjani, R. Moshrefi, H. Mostaanzadehand, J. Shayeh, RSC Adv., 4, 20031 (2014).

21. S. K. Saha, P. Ghosh, A. R. Chowdhury, P. Samanta, N. Murmu, A. Lohar, P. Banerjee, Can. Chem. Trans., 2, 381 (2014).

22. E. Yousif, A. Al-Maamar, B. Abdullah, Yanbu Journal of Engineering and Science, 70, 7 (2013).

[RJC-1632/2017] 